\title{
SISTEM PAKAR ANALISA KERUSAKAN PADA SEPEDA MOTOR HONDA BEAT INJECTION DENGAN METODE BACKWARD CHAINING
}

\author{
Ahmad Yani; Ali Rachman \\ AMIK Bina Sarana Informatika Jakarta,STMIK Nusa Mandiri Jakarta \\ ahmad.amy@bsi.ac.id, ali.rachmanz@yahoo.com;
}

\begin{abstract}
Abstrak
Sistem Pakar adalah merupakan salah satu dari bagian unsur kecerdasan buatan yang dirancang untuk dapat membantu menirukan keahlian seseorang pakar dalam menjawab berbagai pertanyaan dan dapat menyelesaikan suatu pokok masalah yang terjadi. Aplikasi ini di buat untuk dapat mengetahui berbagai penyebab-penyebab kerusakan yang didapat dari gejala-gejala yang sering ditemui oleh para pengguna sepeda motor. Pembuatan aplikasi ini mennggunakan metode backward chaining, yaitu sebuah metode pelacakan kebelakang, yang bekerja berdasarkan kesimpulan yang ada untuk dapat mengetahui penyebabpenyebab yang terjadi. Pengumpulan data dalam penelitian ini menggunakan metode wawancara, yaitu mewawancarai langsung para pakar yang terlibat langsung dalam sistem yang sudah berjalan, pengamatan langsung, serta melakukan studi pustaka terhadap referensi-referensi yang mendukung dalam menjelaskan unsur-unsur yang di teliti. Tujuan dari pembuatan aplikasi ini adalah untuk membantu para mekanik atau teknisi dalam menganalisa berbagai kerusakan sepeda motor Honda Beat Injection pada bengkel Honda Festival Motor dengan proses waktu yang lebih cepat.
\end{abstract}

Kata kunci : Sistem Pakar, Backward Chaining, Honda Beat Injection

\begin{abstract}
Expert system is one part of artificial intelligence designed to mimic the expertise of an expert in answering questions and completing a problem. This application made to resolve damages acquired from the symptoms which mostly encountered by motorcyclist. This application created by backward chaining using backward tracking method that works based on conclusions from series of happenings. In this study, collecting the data gained from the experts involved in the existing system by direct interview, direct observation and also from the literatures as references to support the explanation of the elements studied. The objective of this application is to help the mechanics or technicians in analyzing damages occured in Honda Beat Injection motorcycle at the garage in Honda Motor Festival faster.
\end{abstract}

Keyword: Expert System, Backward Chaining, Honda Beat Injection

\section{PENDAHULUAN}

Kebutuhan akan alat transportasi menjadi bagian yang sangat penting dan tak terpisahkan dalam membantu peran manusia sebagai penunjang kebutuhan sehari-hari. Sepeda motor merupakan salah satu jenis alat transportasi utama, yang sangat di gemari dan butuhkan oleh masyarakat saat ini. Sepeda motor juga sudah banyak mengalami perubahan, pengguna sepeda motor di berikan banyak pilihan seiring dengan kemajuan teknologi. Penggunaan sepeda motor di indonesia sangatlah besar manfaatnya, disamping dapat menghemat waktu, mudah digunakan dan juga biaya yang di keluarkanpun cukup terjangkau. Penggunanya pun sangat beragam, dari kalangan pria dan wanita, baik remaja hingga orang dewasa. Hampir semua menggunakan sepeda motor untuk menunjang aktivitas sehari-harinya.

Honda Beat matic injection pertama kali di produksi di Indonesia pada tahun 2007. Ciri khas sepeda motor ini terletak pada desain spakbor depan yang berada di bawah layaknya sperti motor sport. Teknologi mesin Injection adalah suatu metode pencampuran antara bahan bakar dengan udara pada kendaraan bermotor untuk menghasilkan pembakaran yang lebih sempurna di dalam alat bernama injector, dan hasil proses ini tentunya agar motor menjadi lebih irit bahan bakar. Honda Beat menjadi salah satu jenis sepeda motor yang sangat di gemari oleh pengguna, terutama di kalangan remaja, "One Hart" adalah slogan resmi dari PT. Astra Honda Motor, yang dengan cepat merespon tingkat kebutuhan konsumen pengguna motor Honda yang menyediakan banyak tipe, jenis dan juga varian warna yang menarik dan tentu saja membuat banyak orang tertarik untuk memiliki sepeda motor tersebut. PT. Astra Honda Motor mulai berevolusi dengan sangat cepat, mengikuti perkembangan zaman. Salah satu teknologi yang di keluarkan oleh Honda adalah ESP (Enchanced Smart Power) yaitu sistem yang terintegrasi dengan ACG (Alternating Current Generator) starter yang mampu menghidupkan mesin menjadi lebih halus, kecanggihan teknologi tersebut menjadikan Honda Beat menjadi pilihan yang sangat tepat dalam kemajuan teknologinya. 
Beberapa masalah yang sering terjadi pada motor Honda Beat Injection menurut beberapa pakar yang penulis wawancarai adalah seperti motor sulit atau tidak dapat di starter, mesin yang mendadak mati, dan masih banyak lagi kerusakan yang lain yang muncul akibat kerusakan tersebut tanpa disadari, dapat menghambat dan mengganggu aktivitas penggunanya. Pada beberapa kasus permasalahan kendaraan motor matic, sangat disayangkan pemilik atau pengendara motor, kurangnya pengetahuan tentang masalah dan kerusakan pada motor tersebut yang terjadi dibutuhkan penanganan khusus dari seorang mekanik disebuah bengkel.

Menurut Susanti (2106:54), Teknologi semakin berkembang pesat dengan seiring berjalannya waktu. Komputer yang pada awalnya digunakan sebagai alat hitung, seiring dengan perkembangan zaman komputer banyak digunakan diberbagai bidang misalnya pada bidang militer, ekonomi dan sebagainya. Salah satu pemanfaatan teknologi komputer yaitu dapat digunakan untuk sistem pakar. Setelah penulis mempelajari lebih lanjut dan menganalisa, akhirya muncul permasalahan yang terjadi antara lain sebagian besar pemilik kendaraan motor matic Honda Beat Injection kurang memahami berbagai kerusakan yang terjadi pada sepeda motornya, jumlah tenaga ahli yang tidak banyak dan minimnya pengetahuan seorang teknisi di sebuah bengkel menjadi penyebab utama kesalahan dalam menganalisan kerusakan sepeda motor. Sesuai dengan identifikasi permasalahan yang dianalisa, maka perlunya dibuatkan aplikasi sistem pakar yang mudah dan sederhana dan dapat dipergunakan oleh semua kalangan, baik pengguna motor ataupun mekanik di bengkel tersebut.

\section{LANDASAN TEORI}

\subsection{Kecerdasan Buatan}

Kecerdasan buatan (Artificial Intelegence) merupakan salah satu cabang dari ilmu komputer yang berkonsentrasi pada sistem automatis agar mesin atau komputer dapat melakukan pekerjaan seperti dan sebaik yang dilakukan oleh manusia. Ada tiga tujuan kecerdasan buatan yaitu membuat komputer lebih cerdas, mengerti tentang kecerdasan, dan membuat mesin lebih berguna. Yang dimaksud dengan kecerdasan adalah kemampuan untuk belajar atau mengerti dari pengalaman serta menanggapi dengan cepat dan baik atas sebuah situasi yang baru.

\subsection{Representasi Pengetahuan}

Pengetahuan (knowledge)

dapat diklasifikasikan ke dalam tiga kategori yaitu procedural knowledge, declarative knowledge, dan tacit knowlwdge. Procedural knowledge berkenaan untuk mengetahui bagaimana melakukan sesuatu. Declarative knowledge berkenaan untuk mengetahui sesuatu itu benar atau salah. Sedangkan tacit knowledge tidak dapat diungkapkan dengan bahasa.

\subsection{UML}

UML (Unified Modeling Language) adalah salah satu standar bahasa yang banyak digunakan di dunia industri untuk mendefinisikan requirement, membuat analisis dan desain, serta menggambarkan arsitektur dalam pemograman berorentasi objek.

Menurut Munawar (2005:17) UML merupakan kesatuan dari bahasa pemodelan yang dikembangka oleh Booch, Object Modeling Technique (OMT) dan Object Oriented Software Engineering (OOSE). Metode Booch dari Grady Booch sangat terkenal denang nama metode Design Object Oriented.Pada tahun 1996, Object Management Group (OMG) mengajukan proposal agar adanya standarisasi pemodelan beroreintasi objek dan pada bulan September 1997, UML diakomodasi oleh OMG sehingga sampai saat ini UML telah memberikan kontribusinya yang cukup besar di dalam metodologi beroreintasi objek dan hal-hal yang tekait didalamnya.

\subsection{Visual Basic}

Menurut Andi (2009:23) Ada banyak fasilitas Visual Basic yang sangat berguna bagi anda dalam mengembangkan berbagai program.termasuk didalamnya mengembangkan sistem pakar. Kelebihan lain dari visual basic adalah kemampuannya untuk mengkompilasi program dalam bentuk native code, yaitu optimasi pada saat prosesor mengkompilasi dan menjalankan program tersebut. Keuntungan yang didapat dari native code adalah kecepatannya dalam mengakses program, dimana hal ini hanya dapat anda temui pada aplikasi-aplikasi yang dikompilasi dengan bahasa pemrograman $\mathrm{C}++$. Selain kemampuankemampuan tersebut. visual basic juga menyediakan fasilitas antarmuka penulisan kode program yang lebih mudah dimengerti dan dipakai sehingga berbagai tipe program dapat dikembangkan didalamnya, misalnya EXE, DLL dan OCX bahkan program-program yang berbasis internet.

\subsection{Crystal Report}

Crystal report adalah salah satu peranti lunak yang digunakan khusus untuk membuat laporan. Berbagai fasilitas yang dimilikinya memudahkan dan juga memperindah laporan yang kita buat. Crystal report memiliki berbagai fungsi yang sangat memudahkan dalam pembuatan laporan seperti untuk membuat pengelompokkan data laporan, melakukan proses matematis data laporan, formula dan fungsi untuk berbagai macam kebutuhan, dan lain sebagainya. Crystal report sangat cocok sekali digunakan untuk membuat laporan yang datanya bersumber dari database.

Crystal report dapat digunakan untuk merancang dan menghasilkan laporan daru berbagai sumber data. Beberapa aplikasi lain, seperti Microsoft visual studio, bundle versi OEM dari crystal report sebagai alat pelaporan tujuan umum. Crystal report sebuah aplikasi yang digunakan untuk membuat laporan dari berbagai 
sumber data. Sumber data maksudnya bisa dikatakan database, jadi dengan crystal report bisa membuat laporan yang data-datanya diperoleh dari database apapun, misalnya SQLServer, Microsoft Access, Mysql, dll. Namun terlepas databasenya apa, yang penting selama database itu terkoneksi dengan crystal report maka bisa membuat laporan di crystal report.

\subsection{Model Pengembangan Sistem}

Pengembangan Pakar menurut Arhami (2004:3) Sistem pakar adalah salah satu cabang dari kecerdasan buatan yang membuat penggunaan secara luas pengetahuan (knowledge) yang khusus untuk penyelesaian masalah tingkat manusia yang menjadi pakar.

Seorang pakar adalah orang yang mempunyai keahlian dalam bidang tertentu yaitu pakar yang mempunyai knowledge atau kemampuan khusus, orang lain tidak menggetahui atau mampu dalam bidang yang dimilikinya. Dalam perancangan sistem pakar analisa kerusakan sepeda motor matic Honda Beat Injection, penulis menggunakan metode inferensi backward chaining atau pelacakan kebelakang. Pelacakan kebelakang adalah pendekatan yang dimotori tujuan (goal driven). Dalam pendekatan ini pelacakan dimulai dari tujuan, selanjutnya dicari aturan yang memiliki tujuan tersebut untuk mendapat kesimpulannya, prosesnya berlanjut sampai semua kemungkinan ditemukan.

\subsection{Penelitian Terkait}

Menurut Dahria (2011:199) Sistem pakar yang baik dirancang agar dapat menyelesaikan suatu permasalahan tertentu dengan meniru kerja dari para ahli. Dengan sistem pakar, orang awam pun dapat menyelesaikan masalah yang cukup rumit yang sebenarnya hanya dapat diselesaikan dengan bantuan para ahli. Bagi para ahli, sistem pakar juga akan membantu aktivitasnya sebagai asisten yang sangat berpengalaman. Menurut Saputra dkk (2016:85) dengan seiringnya berjalan waktu, sepeda motor juga memerlukan perawatan agar tetap bisa digunakan. Banyak pengendara sepeda motor tidak mengetahui kerusakan pada sepeda motor tersebut. Kerusakan akan menjadi fatal bila tidak ditangani dengan cepat. Oleh karena itu, kami membuat aplikasi untuk menganalisis jenis kerusakan sepeda motor berdasarkan gejala-gejala fakta dengan menggunakan sistem pakar

\section{METODE PENELITIAN}

Adapun metode penelitian yang digunakan dalam penelitian ini terdiri dari Metode pengembangan sistem waterfall yang meliputi tahanpan berikut.

\section{a. Analisa Sistem}

Setelah penulis dapat mengidentifikasi permasalahan yang ada dan juga batasbatasannya, penulis melakukan analisis terhadap kebutuhan sistem untuk menyelesaikan permasalahan yang ada dan mengetahui apa saja yang dibutuhkan untuk sistem baru yang akan dibuat.

\section{b. Perancangan Aplikasi}

Pada tahap ini proses perancangan aplikasi sistem pakar sesuai dengan kebutuhan user menggunakan bahasa pemrograman computer dalam hal ini visual basic.

\section{c. Uji Coba dan Evaluasi}

Pada tahap ini dilakukan pengujian sistem aplikasi oleh user dan dilakukan evaluasi terhadap kebutuhan user. Tahap pengujian dilakukan untuk menentukan hasil dari perancangan berjalan baik atau tidak.

\section{d. Dokumentasi dan Penulisan Laporan}

Setelah proses implementasi dilakukan, hal yang dilakukan adalah mengumpulkan dokumen dan pembuatan laporan dari tahap identifikasi masalah sampai kesimpulan dari pengujian. Agar dapat di tarik kesimpulan terhadap kegiatan penulisan yang telah dilalui. Kesimpulan yang dibuat untuk menjawab pertanyaan yang terhadap permasalahan sebelumnya.

Sedangkan untuk teknik pengumpulan data dilakukan dengan beberapa cara sebagai berikut:

\section{a. Observasi}

Pada teknik ini penulis melakukan pengamatan secara langsung yang dilakukan di bengkel resmi Honda yang berada di Jalan Pawon Raya Nomer 15 Perumnas Tangerang, yang bernama bengkel Honda Festival AHAS 10069. Sehingga penulis mendapatkan data yang akurat dari tempat observasi.

\section{b. Wawancara}

Proses Wawancara adalah suatu teknik pengumpulan data dengan pembicaraan langsung antara pewawancara (dalam hal ini penulis) dan yang di wawancarai (subjek wawancara). Subjek wawancara adalah bapak Sarwanto sebagai kepala teknisi, bapak Umar sebagai wakil kepala teknisi, dan bapak Syamsul sebagai teknisi, serta kepada para pemilik sepeda motor.

\section{c. Studi Pustaka}

Penulis dalam hal ini melakukan pengumpulan data dan informasi sebanyak-banyaknya dari majalah, buku-buku, berbagai jurnal dari internet dan sumber-sumber bacaan yang lain yang erat kaitannya dengan tema yang diambil dalam penulisan skripsi.

\section{HASIL DAN ANALISA}

\subsection{Pengembangan Sistem Pakar}

Seperti layaknya pengembangan sistem, pada pengembangan sistem pakar ini diperlukan beberapa tahapan, sebagai berikut:

a. Mengidentifikasi masalah dan kebutuhan

Memahami kondisi awal serta mengkaji masalah dengan akurat yang akan dibuat 
aplikasinya dan apakah dengan adanya sistem pakar dapat menjadi solusi suatu masalah.

b. Memahami solusi yang sesuai

c. Beberapa syarat harus terpenuhi agar sistem pakar menjadi solusi yang sesuai dengan kebutuhan.

d. Mempertimbangkan alternative

Ada dua hal yang menjadi alternative yaitu menggunakan sistem komputerisasi yang biasa atau dapat menggunakan sistem pakar.

e. Menghitung biaya investasi dan efisiensi Menghitung biaya pembangunan sistem pakar jika dibandingkan melakukan training in class, dan juga melihat dari segi efisiensi.

f. Memilih alat pengembangan

Menggunakan suatu alat yang sudah dikhususkan oleh pembuat sistem pakar atau dirancang dengan menggunakan bahasa pemograman sendiri seperti Visual basic 6.0.

g. Rekayasa pengetahuan

Proses untuk mendapatkan pengetahuan tentang permasalahan yang dibahas dan akan digunakan sebagai panduan dalam upaya pengembangan. Tahap ini meliputi studi dengan diadakannya pertemuan dengan pakar untuk membahas aspek dari permasalahan.

h. Menguji Sistem

Melakukan proses uji sistem agar proses tersebut mendapatkan hasil yang akurat dan sesuai harapan.

i. Memelihara sistem

Melakukan pembaharuan data maupun informasi yang terkait dengan lingkup pakar agar selalu dapat mengikuti perkembangan.

\subsection{Pengembangan Software}

a. Analisa Kebutuhan Software

Penulis menggunakan jenis Operating system Windows 7 dengan software Visual basic 6.0 untuk membuat desain program analisa sistem kerusakan pada sepeda motor Honda Beat Injection.

b. Desain

Penulis membuat sebuah rancangan database menggunakan Microsoft Access, untuk pembuatan software architecture penulis menggunakan sebuah rancangan dengan Entity Relationship Diagram (ERD) dan untuk user interface menggunakan rancangan visual basic 6.0 .

c. Code Generation

Pada tahapan ini rancangan yang dibuat menggunakan visual basic yang masuk kedalam bahasa pemrograman terstruktur. Pemrograman terstruktur adalah konsep atau paradigma atau tentang sudut pandang pemrograman yang membagi-bagi program berdasarkan fungsi-fungsi atau prosedurprosedur yang sangat dibutuhkan oleh program komputer, ( Rosa dan Salahuddin, 2013:67)

d. Testing

Pada tahapan ini digunakan untuk mengidentifikasikan kelengkapan, keamanan, kualitas dan bebas kesalahan dalam pengembangan software. Dalam pengujian sistem ini akan menggunakan white box testing. Yaitu menguji perangkat lunak dari segi desain dan kode program apakah mampu mengasilkan fungsi-fungsi masukan dan keluaran yang sesuai dengan kebutuhan. Pegujian kotak putih (white box testing) dilakukan dengan memeriksa lojik dari kode program.

e. Support

Support merupakan tahapan akhir dari metodologi pengembangan software. Pada tahapan ini aktivitas yang dilakukan adalah mendukung terhadap sistem yang sedang berjalan dan mengawasi kesalahan-kesalahan yang terjadi pada sistem berjalan.dengan berkembanganya kecanggihan software dan hardware maka sistem yang telah dibuat akan semakin baik.

\subsection{Algoritma sistem pakar}

Sesuai dengan tema yang penulis bahas, berikut ini adalah algoritma dari sistem yang akan penulis rancang adalah sebagai berikut :

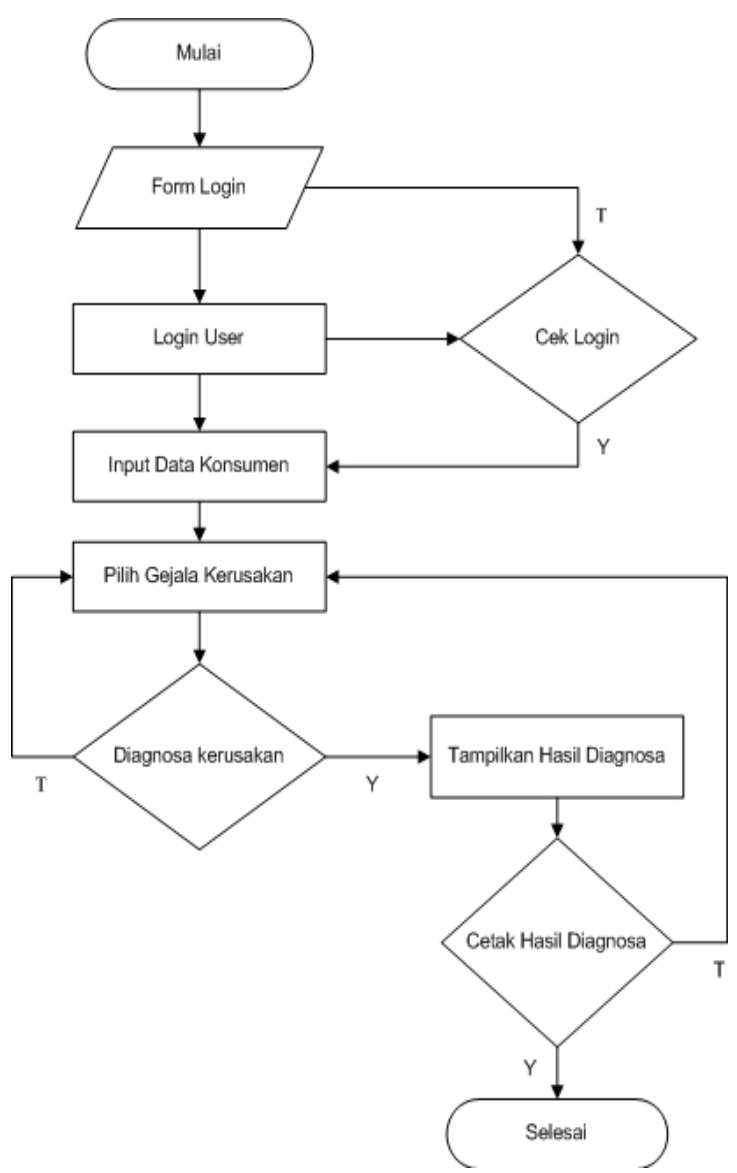

Gambar IV.1. Algoritma Sistem Pakar

\section{Rule-rule Pada Pakar}

Data yang telah diperoleh terlebih dahulu dibuatkan rulenya atau aturan main, sehingga masalah yang ada dapat lebih mudah untuk diselelesaikan dan dilakukan penelusuran nya. Aturan-aturan yang digunakan dalam sistem pakar adalah sebagai berikut : 
Tabel IV.1. Rule Sistem Pakar

\begin{tabular}{|c|c|c|}
\hline No. & Rule & Pernyataan \\
\hline 1. & 1 & $\begin{array}{l}\text { IF Mesin berputar tetapi tidak mau } \\
\text { hidup.DTC (Diagnostic Trouble } \\
\text { Code) dan MIL (Mallfunction } \\
\text { Indicator Lamp) THEN area } \\
\text { kerusakan pada sistem PGM-FI }\end{array}$ \\
\hline 2. & 2 & $\begin{array}{l}\text { Mesin berputar atau tidak mau hidup } \\
\text { (tidak adanya suara bekerjanya } \\
\text { pompa bahan bakar pada saat kunci } \\
\text { kontak diputar ON, THEN area } \\
\text { kerusakan pada sistem PGM-FI }\end{array}$ \\
\hline 3. & 3 & $\begin{array}{l}\text { Mesin mati terus, sulit } \\
\text { dihidupkan,putaran stationer kasar } \\
\text { THEN area kerusakan pada sistem } \\
\text { PGM-FI }\end{array}$ \\
\hline 4.. & 4 & $\begin{array}{l}\text { Ada backfiring (nembak-nembak) } \\
\text { atau misfiring (brebet) pada waktu } \\
\text { akselerasi THEN area kerusakan } \\
\text { pada sistem PGM-FI }\end{array}$ \\
\hline 5. & 5 & $\begin{array}{l}\text { Performa buruk (kemudahan } \\
\text { dikendarai) dan pemakaian bahan } \\
\text { bakar boros THEN area kerusakan } \\
\text { pada sistem PGM-FI }\end{array}$ \\
\hline 6. & 6 & $\begin{array}{l}\text { Putaran stationer mesin dibawah } \\
\text { THEN area kerusakan pada sistem } \\
\text { PGM-FI }\end{array}$ \\
\hline 7. & 7 & $\begin{array}{l}\text { Putaran stasioner mesin diatas } \\
\text { spes/Fikasi THEN area kerusakan } \\
\text { pada sistem PGM-FI }\end{array}$ \\
\hline 8. & 8 & $\begin{array}{l}\text { MIL menyala terus atau MIL tidak } \\
\text { menyala sama sekali (mesin bekerja } \\
\text { secara normal) THEN } \text { area } \\
\text { kerusakan pada sistem PGM-FI }\end{array}$ \\
\hline 9. & 9 & $\begin{array}{l}\text { MIL menyala terus (mesin bekerja } \\
\text { secara normal dan tidak ada DTC } \\
\text { THEN area kerusakan pada sistem } \\
\text { PGM-FI }\end{array}$ \\
\hline 10. & 10 & $\begin{array}{l}\text { Tegangan primer coil pengapian } \\
\text { tegangan puncaknya rendah THEN } \\
\text { area kerusakan pada sistem } \\
\text { pengapian }\end{array}$ \\
\hline 11. & 11 & $\begin{array}{l}\text { Tegangan primer coil pengapian } \\
\text { tidak ada tegangan puncaknya THEN } \\
\text { area kerusakan pada sistem } \\
\text { pengapian }\end{array}$ \\
\hline 12. & 12 & $\begin{array}{l}\text { Tegangan primer coil pengapian } \\
\text { tegangan puncaknya normal tidak } \\
\text { ada percikan bunga api pada busi } \\
\text { THEN area kerusakan pada sistem } \\
\text { pengapian }\end{array}$ \\
\hline 13. & 13 & $\begin{array}{l}\text { IF lgnition pulse generator,tegangan } \\
\text { rendah THEN area kerusakan pada } \\
\text { sistem pengapian }\end{array}$ \\
\hline 14. & 14 & $\begin{array}{l}\text { Ignition pulse generator tidak ada } \\
\text { tegangan puncaknya THEN area } \\
\text { kerusakan pada sistem pengapian }\end{array}$ \\
\hline 15. & 15 & $\begin{array}{l}\text { Motor starter memutar mesin } \\
\text { perlahan THEN area kerusakan } \\
\text { pada Electric Starter }\end{array}$ \\
\hline 16. & 16 & $\begin{array}{l}\text { Motor starter berputar,tetapi mesin } \\
\text { tidak ikut berputar THEN pada area } \\
\text { Electric Starter }\end{array}$ \\
\hline 17. & 17 & $\begin{array}{l}\text { Relay starter berbunyi klik tetapi } \\
\text { mesin tidak berputar THEN area } \\
\text { kerusakan pada Electric Starter }\end{array}$ \\
\hline 18. & 18 & $\begin{array}{l}\text { IF Tinggi permukaan oli mesin terlalu } \\
\text { rendah, pemakaian oli tinggi THEN } \\
\text { area kerusakan pada sistem } \\
\text { pelumaasan }\end{array}$ \\
\hline 19. & 19 & $\begin{array}{l}\text { IF Kontaminasi Oli THEN area } \\
\text { kerusakan pada sistem pelumasan }\end{array}$ \\
\hline
\end{tabular}

\begin{tabular}{|c|c|c|}
\hline 20. & 20 & $\begin{array}{l}\text { IF Kompresi terlalu rendah, mesin } \\
\text { sulit dihidupkan atau unjuk kerja } \\
\text { buruk pada kecepatan rendah THEN } \\
\text { area kerusakan pada area Cylinder } \\
\text { Head atau valve Cylinder Head atau } \\
\text { valve }\end{array}$ \\
\hline 21. & 21 & $\begin{array}{l}\text { IF Kompresi terlalu tinggi, Over } \\
\text { heating atau knocking THEN area } \\
\text { kerusakan pada area Cylinder Head } \\
\text { atau valve / Cylinder/ Piston }\end{array}$ \\
\hline 22. & 22 & $\begin{array}{l}\text { IF Asap berlebihan THEN area } \\
\text { kerusakan pada area Cylinder Head } \\
\text { atau valve / Cylinder/ Piston }\end{array}$ \\
\hline 23. & 23 & $\begin{array}{l}\text { IF Mesin berisik THEN area } \\
\text { kerusakan pada area Cylinder Head } \\
\text { atau valve / Cylinder/ Piston }\end{array}$ \\
\hline 24. & 24 & $\begin{array}{l}\text { IF Putaran Stationer Kasar THEN } \\
\text { area kerusakan pada area Cylinder } \\
\text { Head atau valve / Cylinderl Piston }\end{array}$ \\
\hline 25. & 25 & $\begin{array}{l}\text { IF Suara tidak normal THEN area } \\
\text { kerusakan pada Crankcase atau } \\
\text { crankshaft dan Final reduction atau } \\
\text { transmisi }\end{array}$ \\
\hline 26. & 26 & $\begin{array}{l}\text { IF Ring piston } \\
\text { macet/menggeser,kerusakan bearing } \\
\text { THEN area kerusakan pada Cylinder } \\
\text { atau Piston }\end{array}$ \\
\hline 27. & 27 & $\begin{array}{l}\text { IF Mesin hidup tetapi sekuter tidak } \\
\text { mau bergerak THEN area kerusakan } \\
\text { pada Kickstater atau drive } \\
\text { pulley/driven pulley/kopling dan Final } \\
\text { reduction atau transmisi }\end{array}$ \\
\hline 28. & 28 & $\begin{array}{l}\text { IF Mesin mati tiba-tiba atau sekuter } \\
\text { merangkak THEN area kerusakan } \\
\text { pada Kickstater atau drive pulley } \\
\text { atau drive pulley atau kopling }\end{array}$ \\
\hline 29. & 29 & $\begin{array}{l}\text { IF Unjuk kerja buruk pada kecepatan } \\
\text { tinggi atau kekurangan tenaga THEN } \\
\text { area kerusakan pada Kickstater atau } \\
\text { drive pulley atau drive pulley atau } \\
\text { kopling }\end{array}$ \\
\hline 30. & 30 & $\begin{array}{l}\text { IF Kebocoran oli THEN area } \\
\text { kerusakan pada Final reduction atau } \\
\text { transmisi }\end{array}$ \\
\hline
\end{tabular}

\subsection{Analisa Kebutuhan Software}

\section{A. Tahapan Analisis}

Diagnosa kerusakan pada sepeda motor Honda Beat pada bengkel ini memiliki halaman admin dan halaman user atau pengguna, dimana pada halaman tersebut memiliki akses untuk menggunakan sistem secara menyeluruh .berikut ini adalah spesifikasi sistem yang diusulkan :

a. Hak Akses User (Teknisi) :

1. Dapat Melakukan entry diagnosa

2. Dapat menampilkan data konsumen

3. Dapat menampiklan data gejala kerusakan

4. Dapat menyimpan,merubah dan, menghapus data hasil diagnosa kerusakan

b. Hak Akses Admin atau Pakar

1. Dapat Membuat Daftar Gejala Kerusakan

2. Dapat Membuat Daftar Diagnosa Kerusakan

3. Dapat Membuat Daftar Pengguna

4. Dapat Membuat Laporan 


\section{B. Use Case Diagram}

1. Use Case Diagram Hak Akses Teknisi

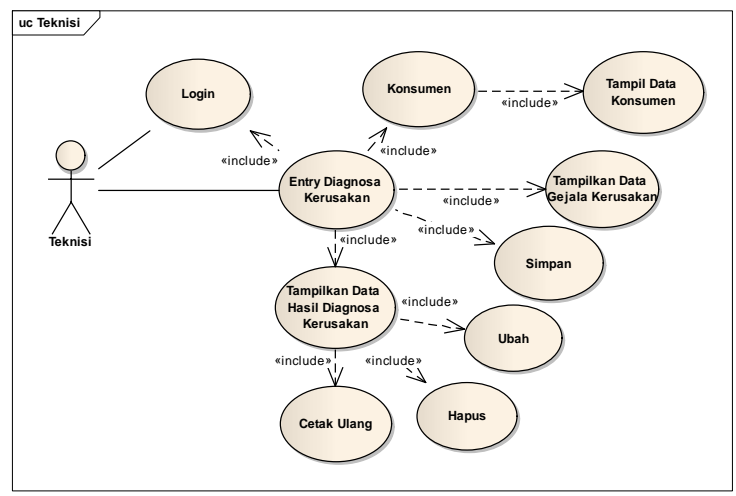

Gambar IV.2. Use Case User atau Teknisi

\section{Use Case Diagram Hak Akses Admin}

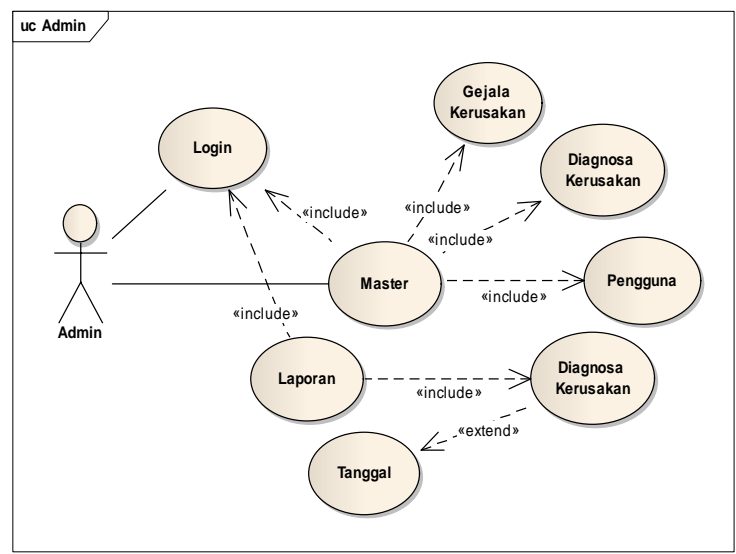

Gambar IV.3. Use Case Admin atau Pakar

Berikut ini akan dijelaskan deskripsi use case yang telah digambarkan yaitu :

1. Deskripsi use case diagram hak akses user atau Teknisi

Tabel IV.2. Tabel Use Case User atau Teknisi

\begin{tabular}{|c|c|}
\hline $\begin{array}{l}\text { Use Case } \\
\text { Name }\end{array}$ & Hak Akses Teknisi \\
\hline Requirment & $\mathrm{A} 1-\mathrm{A} 4$ \\
\hline Goal & $\begin{array}{l}\text { 1. Dapat Melakukan entry diagnosa } \\
\text { 2. Dapat menampilkan data } \\
\text { konsumen } \\
\text { 3. Dapat menampikan data gejala } \\
\text { kerusakan } \\
\text { 4. Dapat menyimpan,merubah dan } \\
\text {,menghapus data hasil diagnosa } \\
\text { kerusakan }\end{array}$ \\
\hline $\begin{array}{l}\text { Pre - } \\
\text { Condition }\end{array}$ & $\begin{array}{l}\text { Teknisi telah melakukan login terlebih } \\
\text { dahulu }\end{array}$ \\
\hline $\begin{array}{l}\text { Post } \\
\text { Condition }\end{array}$ & $\begin{array}{l}\text { User dapat menyimpan hasil diagnosa } \\
\text { kerusakan }\end{array}$ \\
\hline $\begin{array}{l}\text { Brief } \\
\text { Description }\end{array}$ & $\begin{array}{l}\text { Use Case log in dapat digunakan saat } \\
\text { pengguna akan mengakses form entry } \\
\text { diagnosa kerusakan }\end{array}$ \\
\hline Primary & Teknisi \\
\hline
\end{tabular}

\begin{tabular}{|c|c|}
\hline Actor & \\
\hline Main Flow & $\begin{array}{l}\text { 1. User memasukkan data berupa } \\
\text { nomor polisi } \\
\text { 2. User memasukan nama konsumen } \\
\text { apabila konsumen belum terdaftar. } \\
\text { 3. User Mencheklist daftar gejala } \\
\text { kerusakan } \\
\text { 4. User menyimpan hasil diagnosa } \\
\text { kerusakan apabila ditemukan }\end{array}$ \\
\hline $\begin{array}{l}\text { Alternative } \\
\text { Flow }\end{array}$ & 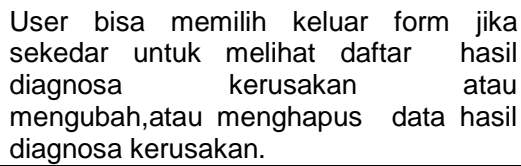 \\
\hline
\end{tabular}

2. eskripsi Use Case diagram hak akses Admin atau Pakar

Tabel IV.3. Tabel Use Case Admin atau Pakar

\begin{tabular}{|c|c|}
\hline $\begin{array}{l}\text { Use Case } \\
\text { Name }\end{array}$ & Hak Akses Teknisi \\
\hline Requirment & $\mathrm{A} 1-\mathrm{A} 4$ \\
\hline Goal & $\begin{array}{l}\text { 1. } \text { Dapat Melakukan entry diagnosa } \\
\text { 2. Dapat menampilkan data } \\
\text { konsumen } \\
\text { 3. Dapat menampikan data gejala } \\
\text { kerusakan } \\
\text { 4. Dapat menyimpan,merubah dan } \\
\text { menghapus data hasil diagnosa } \\
\text { kerusakan }\end{array}$ \\
\hline $\begin{array}{l}\text { Pre - } \\
\text { Condition }\end{array}$ & $\begin{array}{l}\text { Teknisi telah melakukan login terlebih } \\
\text { dahulu }\end{array}$ \\
\hline $\begin{array}{l}\text { Post } \\
\text { Condition }\end{array}$ & $\begin{array}{l}\text { User dapat menyimpan hasil diagnosa } \\
\text { kerusakan }\end{array}$ \\
\hline $\begin{array}{l}\text { Brief } \\
\text { Description }\end{array}$ & $\begin{array}{l}\text { Use Case log in dapat digunakan saat } \\
\text { pengguna akan mengakses form entry } \\
\text { diagnosa kerusakan }\end{array}$ \\
\hline $\begin{array}{l}\text { Primary } \\
\text { Actor }\end{array}$ & Teknisi \\
\hline Main Flow & $\begin{array}{l}\text { User memasukkan data berupa } \\
\text { nomor polisi } \\
\text { 2. User memasukan nama konsumen } \\
\text { apabila konsumen belum terdaftar. } \\
\text { 3. User Mencheklist daftar gejala } \\
\text { kerusakan } \\
\text { 4. User menyimpan hasil diagnosa } \\
\text { kerusakan apabila ditemukan } \\
\end{array}$ \\
\hline $\begin{array}{l}\text { Alternative } \\
\text { Flow }\end{array}$ & $\begin{array}{l}\text { User bisa memilih keluar form jika } \\
\text { sekedar untuk melihat daftar hasil } \\
\text { diagnosa ka kerusakan } \\
\text { mengubah,atau menghapus data hasil } \\
\text { diagnosa kerusakan. }\end{array}$ \\
\hline
\end{tabular}

\subsection{Desain}

Desain merupakan bagian terpenting dari sistem pada tahap ini akan menjelaskan tentang desain database, desain sofware architecture dan desain interface. 


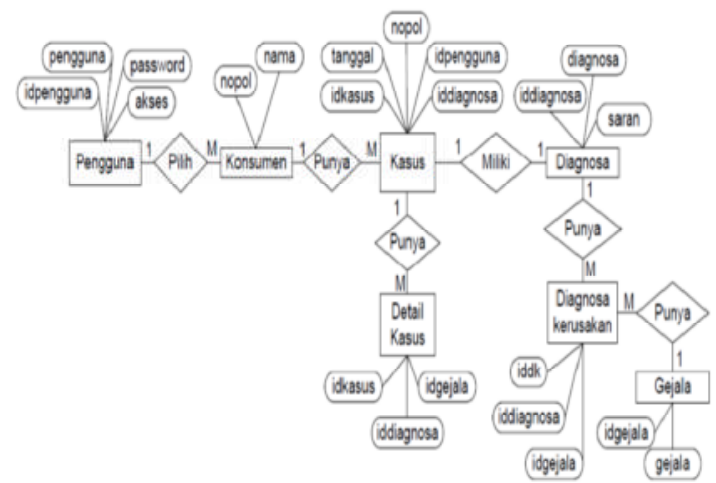

Gambar IV.3. ( ERD ) Entity Relationship Diagram

\section{A. Component Diagram}

Berikut bentuk dari component diagram yang diusulkan yaitu:

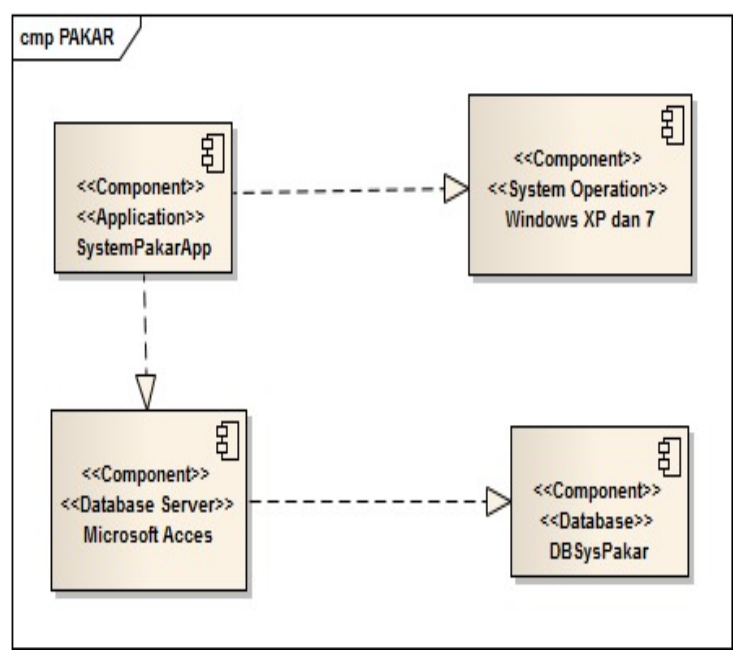

Gambar IV.9. Component Diagram

\section{B. Deployement Diagram}

Berikut bentuk dari Deployment diagram yang diusulkan yaitu :

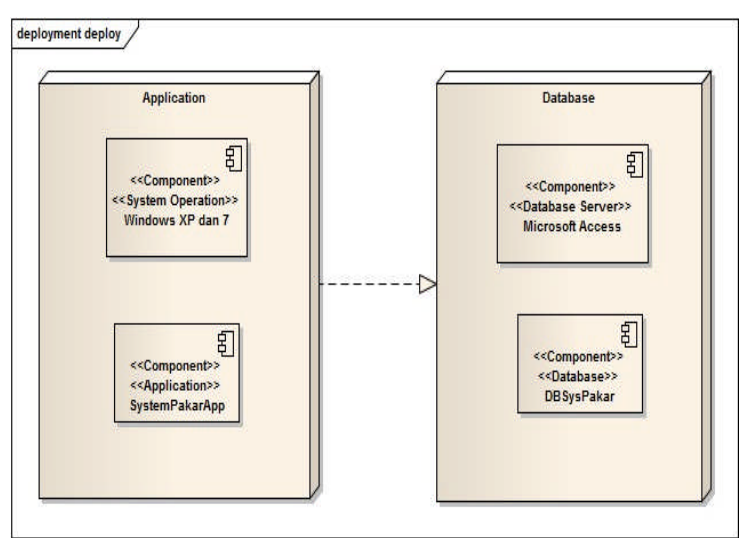

Gambar IV.10. Deployment Diagram

\section{User Interface}

Berikut ini berupa hasil tampilan Form yang telah dibuat yaitu :

a. Form Login User

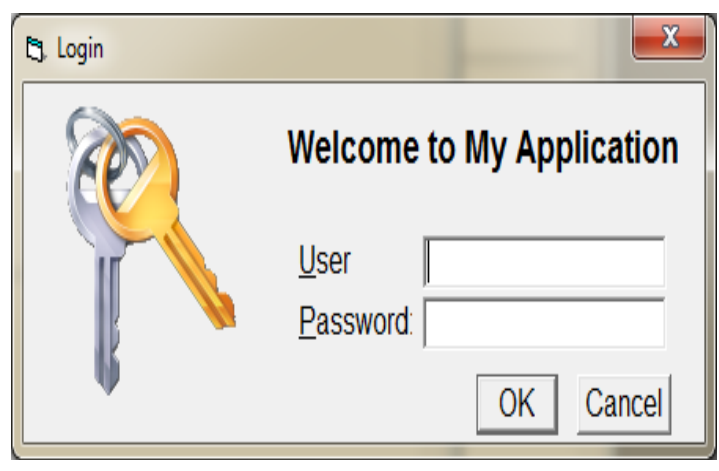

Gambar IV.11. Form Login User

a. Form Entry Diagnosa

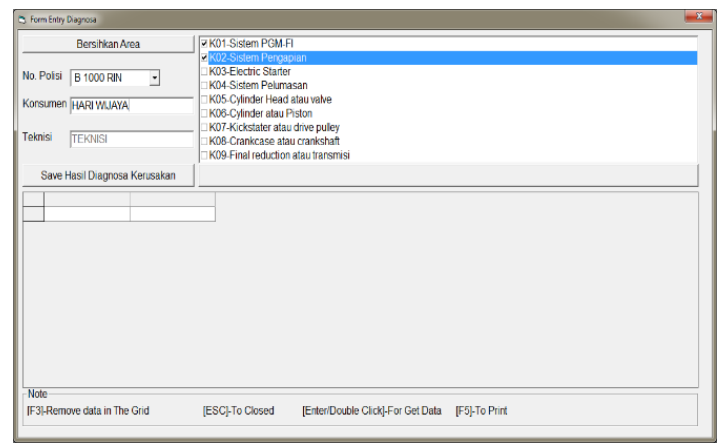

Gambar IV.12. Form Entry Diagnosa

a. Form Cetak Hasil Diagnosa

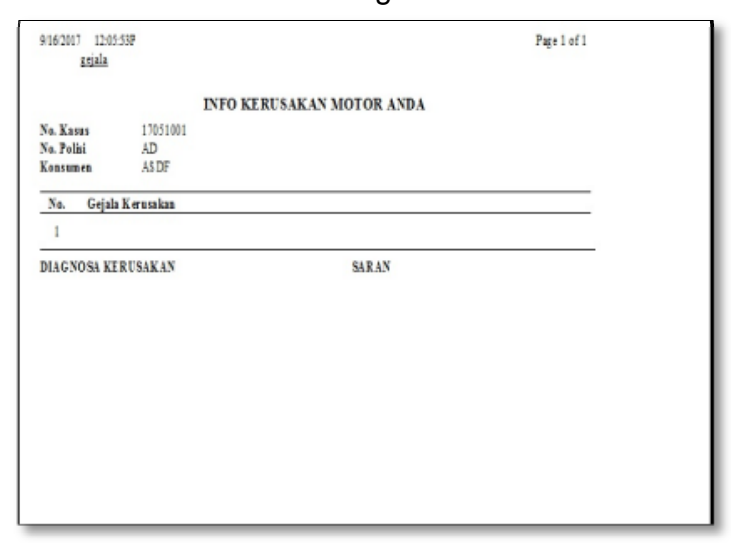

Gambar IV.13. Cetak Hasil Diagnosa

\section{KESIMPULAN DAN SARAN}

\subsection{Kesimpulan}

Proses pembuatan aplikasi sistem pakar analisa kerusakan pada sepeda motor dapat membantu masyarakat secara umum untuk mengetahui penyebab kerusakan yang terjadi pada kendaraan mereka masing-masing. Adapun manfaat secara khususnya yaitu bagi sebuah bengkel yang menggunakan aplikasi sistem pakar ini adalah bisa menghemat waktu analisa kerusakan sepeda motor dalam proses penanganan service kepada konsumen dan menyeragamkan tentang pengetahuan akan kerusakan sepeda motor pada bengkel tersebut kepada seluruh 
mekanik yang ada pada bengkel tersebut, dan juga menghindari adanya salah analisa kerusakan oleh mekanik yang statusnya baru bekerja atau masih menjadi junior mekanik.

Pada pembuatan sistem pakar analisa kerusakan sepeda motor ini didapat beberapa kesimpulan sebagai berikut :

a. Aplikasi sistem pakar dapat membantu masyarakat secara umum untuk mengetahui penyebab kerusakan yang terjadi pada kendaraan sepeda motor mereka masingmasing.

b. Aplikasi sistem pakar dapat membantu yaitu bagi sebuah bengkel yang menggunakan aplikasi sistem pakar ini bisa menghemat waktu analisa kerusakan sepeda motor dalam proses penanganan service kepada konsumen.

c. Aplikasi sistem pakar dapat membantu yaitu bagi sebuah bengkel dalam hal penyeragaman tentang pengetahuan akan kerusakan sepeda motor.

d. Aplikasi sistem pakar dapat membantu menghindari adanya salah analisa kerusakan oleh mekanik, terutama oleh mekanik yang statusnya baru bekerja atau yang masih junior mekanik.

\subsection{Saran-saran}

Saran-saran dalam proses pengembangan sistem informasi pembelajaran berbasis e-learning adalah sebagai berikut :

a. Aplikasi sistem pakar harus didukung dengan Sumber Daya Manusia (SDM) yang memadai.

b. Aplikasi sistem pakar Aplikasi sistem pakar membutuhkan infrastruktur yang memadai seperti komputer.

c. User sebagai pemakai mempunyai peranan untuk pengembangan sistem lebih lanjut.

d. Aplikasi sistem pakar harus selalu di update tentang knowledge base, agar permasalahan yang mungkin suatu saat muncul dan kerusakan tersebut belum bisa ditangani oleh aplikasi ini dikarenakan aturannya belum terdapat dalam database bisa segera dimasukkan dan di update kedalam aplikasi ini.

\section{DAFTAR PUSTAKA}

[1] Arhami, Muhammad. 2005. Konsep Dasar Sistem Pakar Yogyakarta : Penerbit Andi.

[2] S. Rosa A, dan M Salahudin. 2016. Rekayasa Perangkat Lunak. Bandung: Penerbit Informatika

[3] Dahria, Muhammad. 2011 Pengembangan Sistem Pakar dalam Membangun Suatu Aplikasi. Jrunal Saintikom 2011 Vol.10, No.3. 199-205 diambil dari :

https://lppm.trigunadharma.ac.id/public/.../hp6 33-Jurnal-DAR-Sistem\%20Pakar.pdf

[4] Shusanti Maria. 2014. Sistem Pakar Untuk Mendetksi Kerusakan Pada Sepeda Motor 4-tak dengan Menggunakan Metode Backward Chaining ISSN: 2087-2062 Bandar Lampung : Explore Jurnal Vol.4, No.2 Juni 2014 : 5460.diambil dari jurnal.ubl.ac.id/index.php/explore/article/view/5 $40 / 507$

[5] Kusrini. 2006. Sistem Pakar Teori dan Aplikasi Yogyakarta : Penerbit Andi

[6] Munawar.2005. Pemodelan Visual dengan UML Yogyakarta : Graha IImu.

[7] Penerbit Andi. 2009. Pengembangan Sistem Pakar menggunakan Visual Basic: Yogyakarta.

[8] Priyadi, Yudi. 2013. Kolaborasi SQL \& ERD dalam implementasi Database Yogyakarta: Liris.

[9] Saputra, Angga Sulhan, Jati, Bayu Kuncoro , Utomo, Sumdoro Fajar. 2016.Aplikasi Analisa Masalah Mesin Motor Bebek Menggunakan Metode Backward Chaining. ISSN:2302-3805 Yogyakarta : Open Jurnal System Vol.4,No.1 Februari 2016 : 3.4-90. diambil dari: http://ojs.amikom.ac.id/index.php/semnastekn omedia/article/view/120 